\title{
O Direito à Saúde da População LGBT: Desafios Contemporâneos no Contexto do Sistema Único de Saúde (SUS)
}

\author{
LGBT Population's Right to Health: Contemporary Challenges in the Context of Brazilian \\ National Health Service (SUS)
}
El Derecho a la Salud de la Población LGBT: Desafíos Contemporáneos en el Contexto del Sistema de Salud Pública de Brasil (SUS)

\author{
Izabella Rodrigues Melo ${ }^{1}$ \\ Thatiane Hellen de Amorim \\ Raquel Braga Garcia \\ Larissa Polejack \\ Eliane Maria Fleury Seidl \\ Universidade de Brasilia (UnB)
}

\begin{abstract}
Resumo
O direito à saúde da população LGBT brasileira recebeu maior atenção a partir de 2004. Entretanto a efetivação dessas políticas de Estado se encontra prejudicada, como apontam estudos desenvolvidos na segunda década do século XXI. Esta revisão de literatura entra nesse escopo de pesquisas, partindo do artigo "Homossexualidade e o direito à saúde: um desafio para as políticas públicas de saúde no Brasil", para avaliar o desenvolvimento das políticas públicas em saúde voltadas para a população LGBT brasileira entre 2013 e 2019. As pesquisas por artigos deram-se nas bases de dados Biblioteca Virtual em Saúde - Psicologia Brasil (BVS-Psi), SciELO e PsycINFO. Seis dos 81 artigos encontrados preenchiam os critérios de inclusão. Questionou-se como a socialização dos agentes de saúde em contextos LGBTfóbicos leva a práticas contrárias aos princípios das políticas nacionais voltadas para a proteção dos direitos à população LGBT. Propõe-se fortalecimento das ações educativas voltadas para dissolução de preconceitos.
\end{abstract}

Palavras-chave: LGBT, Sistema Único de Saúde, processo transexualizador, direito à saúde, revisão integrativa

\section{Abstract}

The Brazilian LGBT population's right to health received more attention as of 2004. However, as studies developed in the last ten years point out, these State policies are still undermined. This literature review enters this research scope considering the article "Homossexualidade e o direito à saúde: um desafio para as políticas públicas de saúde no Brasil" (Homosexuality and the right to health: a challenge for the health public policies in Brazil) to evaluate the changes in the LGBT population's healthcare between 2013 and 2019. We researched in the databases "Biblioteca Virtual em SaúdePsicologia Brasil" (BVS-Psi), SciELO, and PsycINFO. Out of 81 articles, six of them fulfilled the inclusion criteria. How the socialization of health agents in LGBT-phobic contexts causes their practices to contradict the national policies for the protection of the LGBT population was questioned. The proposal is to strengthen educational actions to mitigate prejudices

Keywords: LGBT, Brazilian National Health Service (Sistema Único de Saúde), transexualizing process, right to health, integrative review

\section{Resumen}

El derecho de la población LGBT brasileña a la salud recibió mayor atención el 2004. Sin embargo, según estudios conducidos a partir de 2010, esas políticas estatales aún se ven perjudicadas. Esta revisión de la literatura entra en el ámbito de investigación, considerando el artículo "Homossexualidade e o direito à saúde: um desafio para as políticas públicas de saúde no Brasil" (Homosexualidad y derecho a la salud: un desafío para las políticas públicas de salud en Brasil), para evaluar la atención médica de la población LGBT entre 2013 y 2019. Las búsquedas se realizaron en las bases de datos Biblioteca Virtual em Saúde - Psicologia Brasil (BVS-Psi), SciELO y PsycINFO. Entre 81 artículos, seis cumplían con los criterios de inclusión. Se cuestionó cómo la socialización de los agentes de salud en contextos LGBT-fóbicos hace que sus prácticas contradigan las políticas de protección

\footnotetext{
${ }^{1}$ Endereço de contato: EQRSW 7/8, lote 1, Edifício Monumental Sudoeste, apartamento 13, Setor Sudoeste, Brasília-DF. CEP 70675-760. E-mail: izabella.rmelo@gmail.com
} 
de los derechos de la población LGBT. Luego, se propone fortalecer acciones educativas para mitigar prejuicios.

Palabras clave: LGBT, Sistema de Salud Pública de Brasil (Sistema Único de Saúde), proceso transexualizador, derecho a la salud, revisión integrativa

\section{Introdução}

As dinâmicas de exclusão social fazem com que grupos marginalizados tenham direitos básicos, tais como saúde e educação, negados (Silva, Nobre, Carvalho Bezerra, Duarte, \& Macedo Quinino, 2017). O fim da segunda década do século XXI não se mostra amigável a diversos grupos de pessoas, como poder-se-ia pensar anos antes. A população LGBT ainda é marginalizada e as vivências dessas pessoas são rotuladas enquanto opções antinaturais. No presente artigo, será utilizada a terminologia LGBT, seguindo o acordo firmado na 1 ạ Conferência Nacional de Gays, Lésbicas, Bissexuais, Travestis e Transexuais (Presidência da República, Secretaria Especial dos Direitos Humanos, 2008).

A não realização da 4a Conferência Nacional de Políticas Públicas e Direitos Humanos de Lésbicas, Gays, Bissexuais, Travestis e Transexuais ilustra os ataques direcionados à comunidade. O evento deveria acontecer em novembro de 2019, de acordo com o Decreto n. 9.453, de 31 de julho de 2018 (Ministério da Mulher, da Família e dos Direitos Humanos, 2018). Também no ano de 2018, o deputado Professor Victório Galli (PSL-MT) propôs o Projeto de Decreto Legislativo n. 1014/18, com o objetivo de impedir a realização da conferência, alegando que esta seria "afronta legal aos bons costumes de uma sociedade justa e moralmente civilizada" (Câmara dos Deputados, 2018). O senador Rogério Carvalho (PT/SE) enviou requerimento ao Ministério da Mulher, da Família e dos Direitos Humanos questionando quando será realizada a 4ạ Conferência LGBT (Brasil, 2019). No entanto, até 15 de novembro de 2019, ainda não houve manifestação do referido ministério e o evento ainda não ocorreu.

A organização heterocisnormativa ${ }^{2}$ da sociedade permite apenas aos sujeitos respondentes a esse padrão determinarem os polos de certo e errado. Por isso, ainda se mostram necessárias as lutas de grupos LGBT para terem seus direitos garantidos, inclusive na área de saúde, onde o atendimento é prestado também por pessoas cujos comportamentos foram desenvolvidos em contextos sociais LGBTfóbicos ${ }^{3}$, estruturados em valores religiosos e naturalizantes (Santos, Santos, Souza, Boery, \& Yearid, 2015; Silva et al., 2017).

O último Relatório sobre Violência Homofóbica no Brasil (Secretaria Especial de Direitos Humanos, 2016), referente ao ano de 2013, elenca os principais tipos de violências aos quais está exposta a população LGBT. A violência psicológica é a mais prevalente, contabilizando 40,1\% das denúncias, seguida pela discriminação, com 36,4\%, e por violências físicas, com $14,4 \%$. Um dos dados mais alarmantes desta pesquisa revela que as discriminações por orientação sexual e por identidade de gênero são os tipos de violações discriminatórias mais cometidas contra a população LGBT, somando 92,2\% das denúncias. Esses números tornam evidente o nível em que se encontra o desconhecimento da sociedade brasileira em relação às vivências que saiam do eixo heterossexual e cisgênero.

\footnotetext{
${ }^{2}$ O termo é usado de acordo com a proposta de Silva et al. (2017). Os autores referem-se à organização social ordenada a partir da cisgeneridade e da heterossexualidade, que não compreendem outras formas de existência.

${ }^{3}$ O termo é usado de acordo com a proposta da Associação Nacional de Travestis e Transexuais (2017).
} 
Seguimentos conservadores da sociedade brasileira rotulam como estranho e digno de marginalização tudo aquilo que não conseguem compreender. Dentro do nosso imaginário, ainda é comum a confusão entre identidade de gênero e orientação sexual, de forma que todas as pessoas LGBT são colocadas em uma mesma categoria e desrespeitadas com a mesma virulência. Para quem se propõe a trabalhar com populações específicas, é necessário fazer ajustes às idiossincrasias daquele grupo, buscando assegurar equidade e inclusão daquelas pessoas (Angonese \& Lago, 2017).

Arán, Murta e Lionço (2009) ilustram essa proposição ao discutirem a inserção de pessoas transgêneras ${ }^{4}$ no sistema de saúde. As autoras apontam para a importância de se extrapolar o posicionamento focado na fisiologia desses sujeitos e considerar quais são as representações sociais desse grupo, ainda ligadas à patologização, estigmatização e invisibilização. Somente ao serem ouvidas as vozes das pessoas transgêneras sobre suas necessidades de saúde e integração social, pode-se delinear políticas públicas adequadas.

Polejack, Totugui, Gomes e Conceição (2015) destacam como aspectos históricos, comunitários, econômicos, políticos e culturais influenciam as noções do que é saúde, sendo essas noções pontos de partida para a elaboração de políticas públicas. A partir dessa compreensão, podemos nos implicar enquanto cidadãos, usuários ou profissionais do sistema de saúde, proponentes de demandas relacionadas à garantia de direitos. Torna-se possível a manutenção do Sistema Único de Saúde alinhada com as subjetividades de grupos sociais marginalizados, como a população LGBT.

A Constituição Federal de 1988 estabelece compromisso do Estado Brasileiro com a garantia do direito à saúde pública. Em nosso país, políticas públicas de saúde são elaboradas e colocadas em prática a partir da relação entre Estado e sociedade, sendo os cidadãos compreendidos como agentes de monitoramento (Polejack et al., 2015).

O Sistema Único de Saúde do Brasil foi instituído pela Lei 8.080, de 19 de setembro de 1990. No corpo do texto da lei, no artigo 2oㅡ, lê-se que a saúde é entendida enquanto direito humano fundamental e que é dever do Estado promover o gozo de tal direito. No parágrafo 1 을 deste artigo, especifica-se que políticas econômicas e sociais devem ser elaboradas com o objetivo de promover qualidade de vida aos cidadãos, devendo o acesso ser universal e igualitário. Os autores da lei também reconheceram que variáveis diversas, a exemplo de alimentação, moradia e trabalho, são determinantes para organizar a saúde dos brasileiros, permitindo que ações de promoção da saúde sejam implementadas (Lei 8.080, 1990). Entende-se por promoção da saúde o fomento de práticas que visem ao aumento da saúde e do bem-estar, por meio da mudança de variáveis ligadas a problemas de saúde, sejam elas individuais, sejam elas sociais (Czeresnia, 2009).

O Capítulo II da Lei 8.080 (1990) versa especificamente sobre os princípios e as diretrizes fundamentais do Sistema implementado. O artigo 198 da Constituição Federal é evocado e complementado com os princípios de universalidade de acesso aos serviços de saúde, integralidade da assistência, preservação da autonomia dos sujeitos, igualdade na assistência, direito à informação, utilização da epidemiologia e participação da comunidade.

Os Princípios de Yogyakarta (2006) pontuam que é dever dos Estados garantir acesso a serviços de saúde física e mental de alta qualidade, não podendo haver nenhuma ordem de

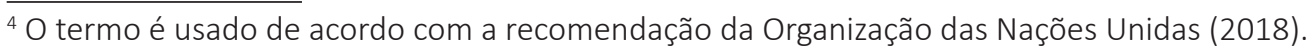


discriminação no atendimento. Os autores do referido documento dizem que a dimensão da sexualidade é parte fundamental da garantia de direitos e, por isso, também é obrigação dos Estados prover instalações e condições adequadas de atendimento para as diferenças de orientação sexual e identidade de gênero. Os Estados têm a obrigação de desenvolver e implementar programas de combate a toda forma de discriminação por orientação sexual ou identidade de gênero, pois as dinâmicas discriminatórias causam prejuízos à saúde daqueles que são marginalizados. Além disso, também é dever estatal promover educação sobre saúde sexual e sobre escolhas concernentes à vivência da sexualidade, com foco no consentimento (Yogyakarta Principles, 2006). O Brasil reconhece, no documento Cadernos de Atenção Básica: Saúde Sexual e Saúde Reprodutiva (Brasil, 2010a), a universalidade dos direitos sexuais. Por essa razão, devem ser propostas políticas públicas que se adequem às "especificidades dos diversos segmentos da população" (p. 17). Os Cadernos também apontam que a diversidade sexual faz com que as situações de saúde (Czeresnia, 2009) difiram entre sujeitos de uma mesma sociedade.

A Política Nacional de Saúde LGBT (PNSLGBT) (Brasil, 2013) foi formulada a partir das propostas do Programa Brasil sem Homofobia e dos Princípios de Yogyakarta e funciona no âmbito do SUS. O objetivo da PNSLGBT foi implementar ações de mudança social, com vistas ao combate à LGBTfobia nos ambientes de atendimento e gestão públicos em saúde. Os proponentes reconheceram como a discriminação e a exclusão sofridas por esse grupo afetam a saúde dos sujeitos que o integram. Para o enfrentamento da discriminação, deve-se promover a democracia social e reforçar o caráter laico do Estado Brasileiro. A Resolução n. 26, de 2017, propõe o segundo Plano Operativo da Política anteriormente mencionada e sustenta-se sobre os eixos de acesso da população LGBT à atenção integral à saúde; promoção e vigilância; educação permanente e mobilização popular; articulação e controle sociais; e monitoramento e avaliação das ações voltadas para a população LGBT.

A Resolução n. 26 (2017) pode ser entendida como resposta governamental às exigências feitas pelos autores da Carta de Brasília (Ministério da Saúde, 2009). O documento foi elaborado a partir de considerações feitas sobre as desigualdades sociais geradas por estruturações sexistas, racistas, adultocêntricas e pelo modelo econômico capitalista, de forma que pessoas e suas dignidades são colocadas como menos importantes do que as possibilidades de geração de lucro. Também se reconhece a intensidade do desenvolvimento do fundamentalismo religioso em nosso país, contrariando a laicidade de nosso Estado e permitindo-se a violação de direitos humanos. Destaca-se a importância da participação popular para a gestão do SUS, de forma a garantir o direito à saúde de todos os cidadãos. Além de exigirem a publicação de planos operativos, os autores demandam que a participação popular no SUS seja garantida e que haja melhoria do atendimento oferecido, de forma a acolher de maneira qualificada as demandas diversas dos cidadãos que buscam os serviços.

Albuquerque, Garcia, Alves, Queiroz e Adami (2013) discutem, em revisão bibliográfica, o estado de vulnerabilidade posto à população LGBT quando se trata do acesso à saúde, em razão do preconceito e discriminação sofridos por essas pessoas. Os autores reconhecem o avanço representado pelo posicionamento oficial do Estado, na forma de leis, planos e resoluções. No entanto questionam a qualidade da efetivação de tais políticas públicas. De forma coerente com o reportado no Relatório de Violência Homofóbica (Secretaria Especial 
de Direitos Humanos, 2016), a discriminação permeia os atendimentos prestados e afasta esses cidadãos da vivência plena de um de seus direitos fundamentais.

As necessidades de saúde da população LGBT ainda são desconhecidas de grande parte dos profissionais de saúde. Sem atendimentos adequados, lésbicas, gays, bissexuais e pessoas transgêneras resistem, cada vez mais, a buscar suporte qualificado em saúde. Entre as reclamações desse grupo, encontra-se a heterocissexualidade assumida. A relação entre usuário e profissional fica prejudicada, dessa forma, e outros prejuízos são causados ao cidadão. Destaca-se a pobreza da comunicação, fator diretamente conectado ao silenciamento de questões relacionadas à sexualidade, à promoção e à prevenção em saúde.

O grande desafio enfrentado atualmente no Brasil, como apontam Mello, Avelar e Maroja (2012), é a transformação das incipientes políticas públicas voltadas à população LGBT, elaboradas com maior afinco a partir do ano de 2004, em efetivas políticas de Estado. Mello et al. (2012) destacam a importância de tais políticas ultrapassarem os planos individuais de governo, de forma que sejam reduzidas as incertezas relativas a, por exemplo, marcos legais de combate à LGBTfobia. A falta de articulação do Congresso Nacional com os parlamentares alinhados com a defesa da população LGBT, de forma a avançar com os debates relativos à criminalização da discriminação dessas pessoas, fez com que fosse necessário o Supremo Tribunal Federal manifestar-se nesse sentido, como aponta a matéria de Moura e Pupo (2019) para o Estadão.

Propõe-se, então, o fomento de reflexões sobre os papéis e crenças dos profissionais de saúde, de forma a melhorar os ambientes de atendimento. Os agentes devem alinhar-se com as políticas governamentais e com as especificidades das populações atendidas. A proposta encontra-se prejudicada, no entanto, na medida em que há poucos estudos nessa temática. Os autores sugerem a realização de novas pesquisas sobre a relação da população LGBT e o SUS, o que possibilitará, inclusive, o aprimoramento das políticas existentes (Albuquerque et al., 2013).

A Psicologia, enquanto área da saúde, é convocada a participar desse processo de manutenção, contribuindo com as políticas públicas a partir das compreensões de fluxos subjetivos e de relações de poderes sociais. Gonçalves (2010, como citado por Polejack et al., 2015) localiza a prática de psicólogas e psicólogos em momentos históricos com demandas diferenciadas. A autora identifica épocas em que trabalhamos com foco na normatização, adequação individual e patologização de questões sociais. Com o tempo, principalmente a partir da década de 1980, direcionamos nossas reflexões e práticas para atender a demandas coletivas, posicionadas politicamente a partir de questionamentos do status quo. Os anos de 1990 foram marcados pelo Projeto de Compromisso Social da Psicologia, fundado na defesa de políticas sociais. A Constituição Federal também foi essencial para embasar a atuação de profissionais da Psicologia com grupos excluídos. Estabelece-se nova relação entre nós e o campo público: nosso conhecimento é disponibilizado para elaborar políticas públicas de Saúde e com a garantia de direitos sociais (Polejack et al., 2015).

Esta revisão integrativa de literatura propôs-se a responder a pergunta: "Como se deu o desenvolvimento das políticas públicas em saúde voltadas para a população LGBT brasileira desde a publicação do artigo 'Homossexualidade e o direito à saúde: um desafio para as políticas públicas de saúde no Brasil', de Albuquerque et al. (2013)?". Objetivou-se avaliar as mudanças ocorridas na atenção à saúde da população LGBT entre 2013 e 2019, ou seja, desde a publicação do artigo referenciado até o ano de 2019. 


\section{Método}

O estudo aqui descrito consiste em revisão integrativa da literatura. Esta modalidade de revisão compreende a articulação de estudos empíricos e teóricos, de forma a evidenciar o estado atual em que se encontram as pesquisas em determinada área. Os conteúdos discutidos pelos autores são analisados e sintetizados em uma redação única, com o propósito de responder aos questionamentos levantados pelo autor da revisão (De Souza, Da Silva, \& De Carvalho, 2010).

Os autores do artigo utilizado enquanto ponto de partida (Albuquerque et al., 2013) realizaram suas pesquisas nas bases de dados Literatura Latino-Americana e do Caribe em Ciências da Saúde (Lilacs) e Scientific Electronic Library Online (SciELO). Os descritores em ciências da saúde (DeCS) escolhidos foram homossexualidade, políticas públicas, assistência integral à saúde, sendo "AND" o operador booleano utilizado para conectá-los. Foram selecionados para análise os manuscritos escritos em língua portuguesa, que versassem sobre a temática do estudo, disponibilizados integralmente on-line e publicados entre 2004 e 2013.

Os autores da presente pesquisa julgaram ser importante realizar mudanças na forma de pesquisar os materiais para este estudo, pois se pretendia ampliar as compreensões sobre os cuidados de saúde de outras pessoas dentro da população LGBT. Assim, os termos usados para busca foram homo, políticas públicas, Sistema Único de Saúde, LGBT. Aos termos "homo" e "LGBT", foi acrescentado o operador booleano *, de truncamento. "Sistema Único de Saúde" foi pesquisado dessa forma e também como "SUS"; para as pesquisas em bases de língua inglesa, utilizou-se "Unified Health System". O operador "AND" teve a função de articular todos os termos. As pesquisas foram realizadas nas bases de dados Biblioteca Virtual em Saúde - Psicologia Brasil (BVS-Psi), SciELO e PsycINFO (organizada pela American Psychological Association).

Artigos brasileiros, empíricos e teóricos, publicados entre 2013 e 2019, com textos completos disponíveis on-line, conectados ao tema desta pesquisa, escritos em línguas portuguesa, inglesa ou espanhola, foram selecionados para esta revisão. Optou-se por excluir teses e dissertações. O período de 2013 a 2019 foi delimitado para permitir a contextualização do desenvolvimento das políticas públicas em saúde para a população LGBT e dos estudos sobre elas nos anos compreendidos entre o estudo do artigo-base e o presente momento.

Os autores da presente pesquisa julgaram ser importante realizar mudanças na forma de pesquisar os materiais para este estudo, pois se pretendia ampliar as compreensões sobre os cuidados de saúde de outras pessoas dentro da população LGBT. Assim, os termos usados para busca foram homo, políticas públicas, Sistema Único de Saúde, LGBT. Aos termos "homo" e "LGBT", foi acrescentado o operador booleano *, de truncamento. "Sistema Único de Saúde" foi pesquisado dessa forma e também como "SUS"; para as pesquisas em bases de língua inglesa, utilizou-se "Unified Health System". O operador "AND" teve a função de articular todos os termos. As pesquisas foram realizadas nas bases de dados Biblioteca Virtual em Saúde - Psicologia Brasil (BVS-Psi), SciELO e PsycINFO (organizada pela American Psychological Association).

Artigos brasileiros, empíricos e teóricos, publicados entre 2013 e 2019, com textos completos disponíveis on-line, conectados ao tema desta pesquisa, escritos em línguas portuguesa, inglesa ou espanhola, foram selecionados para esta revisão. Optou-se por excluir teses e 
dissertações. O período de 2013 a 2019 foi delimitado para permitir a contextualização do desenvolvimento das políticas públicas em saúde para a população LGBT e dos estudos sobre elas nos anos compreendidos entre o estudo do artigo-base e o presente momento.

\section{Resultados e discussão}

O número total de artigos encontrados foi 81. Após leitura dos resumos e dos textos completos, concluiu-se que seis deles preenchiam os critérios de inclusão estipulados pela equipe.

Um terço dos artigos foi escrito no ano de 2017. Os anos de 2013, 2014, 2015 e 2019 são representados por um artigo cada um. Os estudos foram publicados em revistas distribuídas nas seguintes áreas: saúde coletiva (2), saúde HIV/aids (1), políticas públicas em saúde (1), bioética (1) e psicologia (1). Quatro estudos foram classificados como revisões, de naturezas narrativa (2) e integrativa (2). Os demais estudos eram inéditos, sendo um deles realizado a partir de pesquisa empírica, e outro, empírico e documental.

A Tabela 1 apresenta os objetivos estipulados pelos autores e os resultados encontrados por eles nos seis artigos analisados.

Tabela 1

Objetivos e Resultados dos Artigos Pesquisados

\begin{tabular}{|c|c|c|}
\hline Autores/ano & Objetivos & Resultados principais \\
\hline $\begin{array}{l}\text { Freire, Araujo, Souza } \\
\text { \& Marques (2013) }\end{array}$ & $\begin{array}{l}\text { Debater os desafios enfrentados } \\
\text { pela população LGBT no Brasil, } \\
\text { apesar dos avanços, como a for- } \\
\text { malização de programas governa- } \\
\text { mentais e o incremento do debate } \\
\text { público, com enfoque na proble- } \\
\text { mática da saúde no universo TTT, } \\
\text { ressaltando o limitado direito à } \\
\text { saúde e ao acesso a ações e ser- } \\
\text { viços de saúde, o preconceito e a } \\
\text { discriminação sofridos. }\end{array}$ & $\begin{array}{l}\text { Os avanços governamentais são reco- } \\
\text { nhecidos. No entanto destacam-se os } \\
\text { desafios da efetivação do direito à saúde } \\
\text { da população TTT, dado o preconceito } \\
\text { decorrente do despreparo dos profis- } \\
\text { sionais. Além disso, os procedimentos } \\
\text { são prejudicados na medida em que os } \\
\text { recursos tecnológicos disponíveis são } \\
\text { inadequados. }\end{array}$ \\
\hline $\begin{array}{l}\text { Perucchi, Brandão, } \\
\text { Magno, Berto, } \\
\text { Rodrigues, \& } \\
\text { Augusto (2014) }\end{array}$ & $\begin{array}{l}\text { Analisar aspectos psicossociais de } \\
\text { intervenções que pessoas trans- } \\
\text { gêneras realizam em seus corpos, } \\
\text { a partir da investigação do proces- } \\
\text { so de saúde e doença envolvido } \\
\text { nesses contextos. }\end{array}$ & $\begin{array}{l}\text { O atendimento precário foi uma das } \\
\text { maiores reclamações dos participantes } \\
\text { da pesquisa, concretizado, por exemplo, } \\
\text { na não utilização do nome social de tra- } \\
\text { vestis e pessoas transgêneras. Além dis- } \\
\text { so, faltam profissionais qualificados ao } \\
\text { atendimento dessa população. }\end{array}$ \\
\hline $\begin{array}{l}\text { Santos, Santos, } \\
\text { Souza, Boery, \& } \\
\text { Yearid (2015) }\end{array}$ & $\begin{array}{l}\text { Analisar publicações acadêmicas } \\
\text { quanto às ações de atenção à saú- } \\
\text { de de lésbicas, gays, bissexuais, } \\
\text { travestis e transgêneros (LGBTT), } \\
\text { mediante o enfoque da bioética } \\
\text { principialista. }\end{array}$ & $\begin{array}{l}\text { A avaliação dos autores apontou a ne- } \\
\text { cessidade de os profissionais refletirem } \\
\text { sobre seus posicionamentos éticos em } \\
\text { relação à população LGBT, consideran- } \\
\text { do os preconceitos e discriminações so- } \\
\text { fridos por essas pessoas. Entendeu-se a } \\
\text { proposta da bioética principialista como } \\
\text { mais adequada a resolver essa demanda. }\end{array}$ \\
\hline
\end{tabular}




\begin{tabular}{|c|c|c|}
\hline Autores/ano & Objetivos & Resultados principais \\
\hline $\begin{array}{l}\text { Popadiuk, Oliveira, \& } \\
\text { Signorelli (2017) }\end{array}$ & $\begin{array}{l}\text { Analisar como o Processo Transe- } \\
\text { xualizador vem sendo implemen- } \\
\text { tado no SUS e suas convergên- } \\
\text { cias com a Política Nacional de } \\
\text { Saúde Integral de Lésbicas, Gays, } \\
\text { Bissexuais, Travestis e Transexuais, } \\
\text { refletindo-se sobre alguns avan- } \\
\text { ços e desafios. }\end{array}$ & $\begin{array}{l}\text { Identificou-se a nulidade de óbitos e a ga- } \\
\text { rantia de acesso igualitário ao Processo } \\
\text { Transexualizador, em termos regionais. O } \\
\text { desafio mais complexo identificado pelos } \\
\text { pesquisadores foi a perspectiva de redu- } \\
\text { ção ou extinção das políticas públicas de } \\
\text { saúde voltadas à população LGBT. }\end{array}$ \\
\hline $\begin{array}{l}\text { Silva, Nobre, } \\
\text { Bezerra, Duarte, \& } \\
\text { Quinino (2017) }\end{array}$ & $\begin{array}{l}\text { Identificar as ações propostas e } \\
\text { possíveis entraves para a efetiva- } \\
\text { ção de políticas públicas voltadas } \\
\text { à população LGBT. }\end{array}$ & $\begin{array}{l}\text { Apesar de a população LGBT estar em } \\
\text { maior visibilidade, de forma que sejam } \\
\text { propostas políticas públicas voltadas } \\
\text { para sua saúde, a efetivação dessas ainda } \\
\text { é insuficiente. }\end{array}$ \\
\hline $\begin{array}{l}\text { Montenegro, } \\
\text { Velasque, Legrand, } \\
\text { Whetten, Mattos, \& } \\
\text { Rafael (2019) }\end{array}$ & $\begin{array}{l}\text { Discutir as possibilidades de pre- } \\
\text { juízos para a população vivendo } \\
\text { com HIV/aids durante o governo } \\
\text { de Jair Bolsonaro, diante da dimi- } \\
\text { nuição do SUS e do aumento do } \\
\text { setor privado de saúde. }\end{array}$ & $\begin{array}{l}\text { O governo de Jair Bolsonaro, juntamente } \\
\text { a um Congresso majoritariamente con- } \\
\text { servador, promove cortes do financia- } \\
\text { mento de políticas de saúde, educação e } \\
\text { pesquisa. Essas medidas podem implodir } \\
\text { ações de defesa de direitos humanos fo- } \\
\text { cadas em minorias. }\end{array}$ \\
\hline
\end{tabular}

Silva et al. (2017) realizaram mapeamento das políticas públicas voltadas para a população LGBT. Os autores afirmam que essa movimentação estatal sinaliza o reconhecimento da LGBTfobia enquanto variável para a determinação de saúde. O Programa Brasil sem Homofobia, lançado em 2004, tem como objetivo aprimorar a educação e o comportamento dos gestores públicos em relação às populações LGBT, partindo da não discriminação a nenhum sujeito dentro dos serviços públicos de saúde.

A Política Nacional de Atenção Integral à Saúde da Mulher, de 2004, parte do pressuposto de que os trabalhos em saúde não podem ser permeados por nenhuma ordem de preconceito, reconhecendo as especificidades de gênero. O Plano Integrado de Enfrentamento da Feminização da Epidemia de Aids e DSTs, publicado em 2007, objetiva a promoção da qualidade de vida de mulheres, cis e trans, que vivem com HIV/aids. No entanto o Plano não se dedica ao cuidado de homens transgêneros. O Plano Nacional de Enfrentamento da Epidemia de aids e DST entre Gays, HSH e Trans, do mesmo ano, qualificou os esforços de prevenção do HIV/aids dentro de grupos sociais específicos (Silva et al., 2017).

O Processo Transexualizador (PrTr), lançado em 2008 e revisto em 2013, visa à ampliação da concepção de saúde das pessoas transgêneras, buscando integralidade no atendimento em saúde e propagação de informação e conhecimento para a população (Silva et al., 2017). O PrTr busca a integralidade da atenção às pessoas transgêneras, sem se restringir às cirurgias de ressignificação sexual. As intervenções se pautam no trabalho de equipes multidisciplinares, garantindo o acesso dessas pessoas à Atenção Básica e à Atenção Especializada, visando a um atendimento humanizado e livre de discriminação. A Atenção Especializada no PrTr inclui as modalidades de atenção ambulatorial (acompanhamento clínico, pré e pós-operatório e hormonioterapia) e hospitalar (realização de cirurgias e acompanhamento pré e pós-operatório) (Popadiuk et al., 2017). 
Ressalta-se a importância de os profissionais da Atenção Básica estarem também preparados para acolher as demandas das pessoas transgêneras, uma vez que a Atenção Básica é o contexto em que ocorrem os encaminhamentos para atendimentos especializados. Entre janeiro de 2008 e maio de 2016, foram realizados 320 procedimentos hospitalares do Processo Transexualizador, não havendo nenhum óbito. É oportuno observar que parte das pessoas transgêneras não tem interesse em realizar cirurgias de redesignação sexual, não sendo procedimentos definidores de suas identidades (Popadiuk et al., 2017).

O III Programa Nacional de Direitos Humanos (PNDH-3) é uma iniciativa da Secretaria de Direitos Humanos do Governo Federal, consolidada em 2010. O Programa parte do pressuposto de que é responsabilidade do Estado promover políticas centradas na "dignidade da pessoa humana e na criação de oportunidades para que todos e todas possam desenvolver seu potencial de forma livre, autônoma e plena" (Brasil, 2010b). O PNDH-3 é organizado em eixos orientadores, diretrizes, objetivos estratégicos e ações programáticas, bases para a implementação de políticas públicas voltadas para demandas sociais específicas (Silva et al., 2017).

O Eixo 3 do Programa trata da universalização dos direitos em contextos de desigualdades. A sistematização desse eixo deu-se a partir da compreensão das diversidades no alcance da igualdade social, "visando à superação de barreiras estruturais para o acesso aos direitos humanos" (Brasil, 2010b). A Diretriz 10 desse eixo versa sobre a garantia da igualdade na diversidade.

A Política Nacional de Saúde Integral LGBT consiste em plano organizado em diretrizes e objetivos focados no combate à discriminação à população LGBT nos serviços de saúde. Os autores sublinham o preconceito e violências sofridos por esse grupo social enquanto prejudicial à saúde (Silva et al., 2017).

A Conferência Nacional LGBT, em 2008, contou com a presença do então presidente da República, Luiz Inácio Lula da Silva, ministros e representantes do movimento LGBT, fazendo com que o Brasil fosse o primeiro país a realizar uma atividade dessa natureza, demarcando o compromisso do Estado com os direitos dessa população (Freire et al., 2013). A comparação do momento atual com o que havia há onze anos permite a constatação de que não houve melhorias - talvez, possa-se considerar 2019 como sido o ápice do retrocesso em termos da garantia de direitos a minorias sociais.

A nomeação da pastora evangélica Damares Alves para o Ministério das Mulheres, da Família e dos Direitos Humanos representou um retrocesso para os direitos da população LGBT, para a população indígena e para as pessoas vivendo com HIV/aids. O novo ministério se recusou a adicionar a população LGBT como um grupo protegido pelo seu governo, declarando que políticas de diversidade ameaçam a família brasileira (Montenegro et al., 2019).

O novo projeto de governo promove agenda conservadora que pretende proibir o debate acerca das temáticas de sexualidade, gênero e diversidade em escolas, incentivando que essas discussões se restrinjam ao ambiente doméstico, como ressaltam Montenegro et al. (2019). Tal posicionamento do governo, de invisibilização e impedimento dos debates acerca da diversidade sexual, afeta a responsabilidade do Estado em promover políticas públicas de saúde voltadas para a população LGBT. A proibição da disseminação de informações, em decorrência da "ameaça à família brasileira", tal como aponta Damares, mostra-se como retrocesso à população LGBT quando falamos em acesso a saúde. Popadiuk et al. (2017) apon- 
tam que um dos pilares importantes para que pessoas transgêneras tenham seus direitos garantidos por meio do PrTr é o preparo e acesso a informações de toda a equipe de saúde, o que necessita passar por debates de gênero e sexualidade.

Observa-se nas falas de Damares ideias que reforçam os estereótipos de gênero e dificultam o trabalho das políticas públicas voltadas para a população LGBT. Esse posicionamento conservador é observado na primeira declaração da ministra: "Meninas vestem rosa, e meninos vestem azul", afirmando que "não haverá mais doutrinação de gênero para as crianças e adolescentes do Brasil" (Montenegro et al., 2019). Além disso, o atual presidente da República, Jair Bolsonaro, já afirmou publicamente ser homofóbico, declarando que preferia ver seu filho morto em um acidente do que ser gay. O governo federal, aliado ao Congresso mais conservador desde o período do regime militar, pode comprometer os direitos da população LGBT no Brasil, país com maior índice de homicídios LGBTfóbicos e considerado o mais perigoso para as pessoas transgêneras do mundo (Montenegro et al., 2019).

Enquanto a tendência mundial é de queda do crescimento dos casos de HIV/aids, o Brasil segue o rumo oposto e tem um aumento nos casos registrados, principalmente entre homens jovens que fazem sexo com outros homens, tal como destacam Montenegro et al. (2019). É importante ressaltar que o risco e a vulnerabilidade dos homossexuais femininos e masculinos com relação à infecção pelo HIV são resultado da falta de informação, do preconceito e do grande estigma social que recai sobre essa população (Santos et al., 2015).

O atual governo também tem representado retrocessos nas políticas de combate ao HIV. Em janeiro de 2019, o governo de Bolsonaro censurou um manual, desenvolvido pelo Departamento Nacional de Vigilância, Prevenção e Controle de Doenças Sexualmente Transmissíveis, HIV/aids e Hepatites Virais (DDAHV), que abordava a saúde dos homens transgêneros, incluindo estratégias de redução de danos (por exemplo, necessidade de evitar seringas ou agulhas ao usar hormônios). De acordo com o Ministro da Saúde, Luiz Henrique Mandetta, a política de HIV/aids não deve desrespeitar a instituição familiar (Montenegro et al., 2019).

Os posicionamentos atuais do governo se mostram em desacordo com os eixos da Resolução n. 26 (2017), que prevê:

I - Acesso da população LGBT à atenção integral à saúde; II - Promoção e vigilância em saúde; III - Educação permanente, educação popular em saúde e comunicação; IV Mobilização, articulação, participação e controle social; V - Monitoramento e avaliação das ações de saúde para a população LGBT. (p. 2).

Mesmo com os avanços da população LGBT no combate à epidemia de HIV/aids, que assolou sobremaneira esse segmento da população na década de 1980, ainda existem ameaças à população LGBT no combate a essa epidemia. Santos et al. (2015) apontam que os movimentos da população LGBT concentraram-se no combate à discriminação e ao preconceito e na prevenção da incidência no vírus, tanto para a própria comunidade quanto para a população geral. Os autores pontuam que, além do combate à homofobia, o combate à epidemia de HIV/aids contribuiu para a consolidação desses grupos, alvos de grande estigma social e de falta de informação.

Miskolci, Valadão e Gomes (2011, citado em Santos et al., 2015) afirmam que uma das razões para o despreparo dos profissionais da saúde para lidar com a diversidade sexual e de 
gênero está nos acordos construídos e disseminados nas dinâmicas histórico-sociais. As formações técnicas não dispõem de espaços de reflexões críticas sobre o tema. O despreparo dos profissionais prejudica a relação profissional-usuário, inibindo a expressão livre e aberta de pessoas LGBT sobre a temática de sua sexualidade com os profissionais de saúde, com limitações às possibilidades de prestação de cuidado.

Para que seja possível efetivar a mudança proposta pela Política Nacional de Saúde Integral LGBT e proporcionar o correto atendimento à população em sua diversidade, é necessário que os profissionais de saúde passem por revisão de seus pensamentos e posturas éticas. Os códigos de ética de profissões da saúde devem ser observados em suas pontuações enfáticas sobre a não discriminação nos atendimentos. A imposição da heterocissexualidade como o comportamento sexual padrão pode contrariar o princípio da autonomia, uma vez que limita as possibilidades de autodeterminação do usuário, obrigando-o a se submeter a padrões externos de retidão. Uma das formas de promover as mudanças necessárias nos serviços de saúde perpassa pelo questionamento da heterossexualidade como a única possibilidade aceitável de orientação sexual, buscando abarcar as especificidades dos diversos segmentos populacionais (Santos et al., 2015).

É necessário compreender a comunidade LGBT em toda sua complexidade, respeitando a autonomia e diversidade de cada segmento populacional que compõe a sigla. Freire et al. (2013) ressaltam que o pluralismo de siglas engloba grupos de indivíduos que, apesar de movidos por discursos semelhantes, delimitam suas diferenças, sendo estas pouco ou nada compreendidas pela sociedade. Por isso, mostra-se indispensável a reflexão sobre as subjetividades LGBT. Santos et al. (2015) propõem, então, ter na bioética principialista ponto de partida para a atuação profissional em saúde, baseando-se nos princípios de beneficência, não maleficência, respeito à autonomia e justiça (Paranhos, 2017). Assim, pode-se superar os juízos de valor dos profissionais de saúde, promovendo maior igualdade no atendimento da população LGBT.

A pluralidade e diversidade contida nos segmentos populacionais da sigla LGBT representam também diferentes demandas para os serviços de saúde. A problemática de saúde no universo de travestis, transexuais e transgêneros (TTT) engloba mais do que a realização de cirurgias de transgenitalização. O que faz um sujeito se afirmar em um gênero é sua subjetividade. Assim, é possível que a transformação do corpo proveniente da hormonioterapia já seja suficiente para a garantia do sentimento de identidade em pessoas transgêneras (Bento 2006, como citado em Freire et al., 2013).

Os estudos selecionados destacaram a relevância das políticas governamentais para a defesa dos direitos de indivíduos e coletivos com relação à saúde. O Ministério da Saúde elaborou a Carta dos Direitos dos Usuários, compreendendo as demandas de diversos grupos sociais e qualificando os debates na área. Essa política objetiva a ampliação do acesso a serviços adequados, de acordo com os princípios de integralidade e universalidade do SUS, por proporem ações voltadas para a promoção, prevenção e recuperação da saúde (Brasil, 2010 como citado em Freire et al., 2013).

A Carta dos Direitos dos Usuários no SUS é enfática ao abordar o direito ao atendimento humanizado, acolhedor e livre de qualquer discriminação, negação ou restrição, em virtude da orientação sexual e identidade de gênero. Assim, a LGBTfobia é equiparada às discriminações de raça, classe e idade. Entre os direitos assegurados pela carta, encontra-se o de todo 
usuário ser chamado por seu nome social, também utilizado nos registros do SUS (Silva et al., 2017). Entretanto, apesar da existência da Regra Administrativa Federal (n. 1.820, de 13 de agosto de 2009) que garante o uso do nome social, muitas vezes essa exigência não é observada pelos profissionais em suas práticas, lesando um direito que a população LGBT tem e sendo uma das queixas mais significativas relacionadas ao tratamento precário por parte da equipe multiprofissional (Perucchi et al., 2014).

Perucchi et al. (2014) destacaram outra queixa significativa identificada por essa população: a da falta de profissionais especializados para o atendimento da população transgênera, como endocrinologistas, psiquiatras, ginecologistas, urologistas e psicólogos no quadro de pessoal clínico de alta complexidade. O Brasil dispõe de cinco hospitais que realizam atendimentos ambulatoriais e cirúrgicos: Hospital das Clínicas da Universidade Federal de Goiás, Goiânia (GO); Hospital de Clínicas de Porto Alegre, da Universidade Federal do Rio Grande do Sul, em Porto Alegre (RS); Hospital Universitário Pedro Ernesto, da Universidade Estadual do Rio de Janeiro (RJ); Fundação Faculdade de Medicina, da Universidade de São Paulo (USP); e Hospital das Clínicas da Universidade Federal de Pernambuco (UFPE), no Recife (PE) (Brasil, 2017; Popadiuk et al., 2017). Há, também, 23 unidades de atendimento ambulatorial (Coordenação de Promoção de Equidade em Saúde integrante da Gerência de Programas Especiais da SES de Goiás, 2015), espalhadas pelo território nacional. E, apesar da existência desses centros especializados, os tratamentos oferecidos não são integrados. Eles oferecem apenas parte dos serviços recomendados pela legislação vigente, o que coloca esse segmento da população em situação de risco e vulnerabilidade.

Os dados anteriores corroboram as discussões levantadas por Perucchi et al. (2014), segundo as quais, devido à falta de integralidade e à dificuldade de acesso aos serviços, os cidadãos transgêneros ocupam uma posição de maior vulnerabilidade diante do risco da automedicação, uso inadequado e não especializado de hormônios e a inserção corporal de silicone. Tais procedimentos podem levar a danos irreversíveis à saúde do usuário e até ao óbito. É de extrema importância, então, repensar o lugar de vulnerabilidade reservado aos cidadãos transgêneros nos serviços públicos de saúde no Brasil. Apesar de ser modelo mundial em sua organização, a prática do SUS ainda expõe usuários a agravos de saúde (Perucchi et al., 2014).

Diante desse cenário, observa-se como as dificuldades decorrentes do preconceito, enfrentadas por esses indivíduos na sociedade, manifestam-se nos serviços de saúde. As pessoas transgêneras encontram-se em situação especialmente vulnerável, justificando uma política específica de saúde para elas. As pessoas acessam os serviços motivadas pela combinação de aspectos individuais e contextuais, que também serão preditores da qualidade do atendimento recebido (Freire, Araujo, Souza, \& Marques, 2013). Essas reflexões corroboram, assim, as ideias apontadas por Silva et al. (2017), que argumentam como o debate sobre diversidade, promovido a partir das demandas identificadas por gestores e pesquisadores, não se conecta com a atuação dos profissionais em contato direto com os usuários.

A partir da visão em como se dá esse desenvolvimento de políticas públicas em saúde voltadas para a população LGBT brasileira, é possível delinear propostas de trabalho e resoluções que possam tornar esse cenário mais justo, igualitário e saudável para a população LGBT. Lancetti (2007, como citado em Freire et al., 2013) enfatiza a importância de se utilizar a clínica peripatética para o atendimento desse seguimento populacional. A proposta dos autores é de uma prática dialógica e que contemple a fluidez das relações. 
As pessoas transgêneras podem ser mais bem atendidas à medida que se amplia a gama de serviços a elas oferecidos, além daqueles delimitados pelo Processo Transexualizador do SUS. Para tanto, é necessário haver sensibilização dos profissionais às particularidades desse grupo, o respeito ao nome social e a saída do modelo binário para organização de gêneros. Ações formativas, cartazes, promoção de cursos sobre a Política Nacional de Saúde Integral de Lésbicas, Gays, Bissexuais e Transexuais e avaliação e monitoramento dos serviços por atores adequados à tarefa (como os integrantes do Comitê Técnico de Saúde LGBT) também são identificados como formas de aprimorar os serviços oferecidos à população LGBT (Popadiuk et al., 2017).

Os espaços institucionalizados devem ser ocupados por representantes da população LGBT, de forma a exercer-se o controle social no SUS. Essa dinâmica se dá pelo contato com gestores dos níveis municipais, estaduais e federais para a propositura de políticas novas e acompanhamento da implementação das existentes. A vulnerabilidade e a exposição aos riscos desse grupo social fazem com que seja necessário maior afinco nas pressões feitas (Silva et al., 2017). A Lei n. 8.080, de 1990, que instituiu o SUS, no Capítulo II, artigo 7으, define a participação comunitária enquanto um dos princípios do Sistema ali detalhado. 0 Estado Brasileiro reconhece a participação social enquanto fator potente e necessário de enfrentamento às desigualdades características de nossa sociedade, de forma a fortalecer a democracia (Brasil, 2013).

\section{Considerações finais}

As autoras deste estudo observaram a grande quantidade de artigos de revisão de literatura encontrados durante o processo de pesquisa. Sugere-se, a partir disso, a aproximação dos usuários por futuros pesquisadores. A falta de estudos empíricos dificultou a resposta à pergunta feita sobre as mudanças em políticas públicas da população LGBT entre os anos de 2013 e 2019. As autoras reconhecem que não incluíram na pesquisa dissertações de mestrado e teses de doutorado.

Outro ponto a ser considerado refere-se à escassez de estudos sobre outros sujeitos da sigla LGBT, como as pessoas bissexuais. Estas são constantemente invisibilizadas nas discussões públicas e um dos papéis da academia é contribuir para lançar luz sobre essas questões. Conforme constataram Machado, Alves e Dickson (2018), o bissexual, ao relacionar-se com pessoa do mesmo gênero, é lido como gay ou lésbica; a partir do momento que se relaciona com sujeitos do gênero oposto, é identificado como heterossexual. A polarização embutida nesse raciocínio abre espaço para a prática da bifobia. Este preconceito é vivenciado de maneiras distintas por homens e mulheres, colocando essas pessoas em risco quando se trata de suas saúdes sexuais (Moscheta, Fébole, \& Anzolin, 2016).

Salienta-se, por fim, a necessidade de posicionamento da Psicologia nos processos de aprimoramento do SUS, a partir das compreensões de fluxos subjetivos e de relações de poderes sociais. Desde a década de 1980, direcionamos nossas reflexões e práticas para atender a demandas coletivas, posicionadas politicamente a partir de questionamentos do status quo. Estabelece-se, então, uma nova relação entre psicólogas, psicólogos e o campo público: nosso conhecimento é disponibilizado para elaborar políticas públicas de Saúde comprometidas com a garantia de direitos sociais (Polejack et al., 2015). Sugere-se, assim, o 
desenvolvimento de mais estudos sobre o papel da Psicologia no desenvolvimento de políticas de saúde voltadas para a população LGBT.

\section{Referências}

Albuquerque, G. A., Garcia, C. D. L., Alves, M. H. J., Queiroz, C. M. H. T. De, \& Adami, F. (2013). Homossexualidade e o direito à saúde: Um desafio para as políticas públicas de saúde no Brasil. Saúde em Debate, 37(98), 516-524. doi: http://dx.doi.org/10.1590/ s0103-11042013000300015

Angonese, M., \& Lago, M. C. D. S. (2017). Direitos e saúde reprodutiva para a população de travestis e transexuais: Abjeção e esterilidade simbólica. Saúde e Sociedade, 26(1), 256-270.

Arán, M., Murta, D., \& Lionço, T. (2009). Transexualidade e saúde pública no Brasil. Ciência \& Saúde Coletiva, 14(4), 1141-1149.

Associação Nacional de Travestis e Transexuais. (2017). Mapa dos assassinatos de travestis e transexuais. Antra.

Brasil (2010a). Cadernos de atenção básica: Saúde sexual e saúde reprodutiva. Brasília, DF: Ministério da Saúde.

Brasil. (2010b). PNDH-3 - Eixo 3 - Universalizar direitos em um contexto de desigualdades. Disponível em https://pndh3.sdh.gov.br/portal/sistema/navegacao-eixo/eixo/3\#

Brasil. (2013). Ministério da Saúde. Secretaria de Gestão Estratégica e Participativa. Departamento de Apoio à Gestão Participativa. Política Nacional de Saúde Integral de Lésbicas, Gays, Bissexuais, Travestis e Transexuais. Brasília: Ministério da Saúde.

Brasil (2017). Cirurgias de mudança de sexo são realizadas pelo SUS desde 2008 [Website]. Disponível em http://www.brasil.gov.br/cidadania-e-justica/2015/03/ cirurgias-de-mudanca-de-sexo-sao-realizadas-pelo-sus-desde-2008

Brasil. Requerimento (RQS) n. 349, de 2019 - Informações à Ministra de Estado da Mulher, da Família e dos Direitos Humanos. (2019). Brasília.

Câmara dos Deputados. (2018). Proposta susta realização de 4a Conferência Nacional de Políticas Públicas LGBT [Website]. Disponível em https://www.camara.leg.br/ noticias/549802-proposta-susta-realizacao-de-4a-conferencia-nacional-de-politicaspublicas-lgbt/

Coordenação de Promoção de Equidade em Saúde integrante da Gerência de Programas Especiais da SES de Goiás. (2015). Processo Transexualizador - Perguntas frequentes [Blog]. Disponível em https://equidadesaudegoias.wordpress.com/2015/07/14/ processo-transexualizador-perguntas-frenquentes/

Czeresnia, D. (2009). O conceito de saúde e a diferença entre prevenção e promoção. In D. Czeresnia, \& C. M. de Freitas (Org.), Promoção da saúde: Conceitos, reflexões, tendências. Editora Fiocruz.

Freire, E. C., Araujo, F. C. A., Souza, Â. C., \& Marques, D. (2013). A clínica em movimento na saúde de TTTs: Caminho para materialização do SUS entre travestis, transsexuais e transgêneros. Saúde em Debate, 37(98), 477-484. Disponível em http://www.scielo.br/ scielo.php?script=sci_arttext\&pid=S0103-11042013000300011\&lang=pt

Lei Federal n. 8.080, de 19 de setembro de 1990. Dispõe sobre as condições para a promoção, proteção e recuperação da saúde, a organização e o funcionamento dos serviços correspondentes e dá outras providências. Diário Oficial da União, Brasília. 
Machado, J., Alves, A., \& Dickson, M. (2018). A invisibilidade bissexual na novela "O Outro Lado do Paraíso". In IJ08 - Estudos Interdisciplinares da Comunicação do XVII Congresso de Ciências da Comunicação na Região Norte. Vilhena: Sociedade Brasileira de Estudos Interdisciplinares da Comunicação. Disponível em http://portalintercom.org.br/anais/ norte2018/resumos/R59-0208-1.pdf

Mello, L., Avelar, R. B. D., \& Maroja, D. (2012). Por onde andam as políticas públicas para a população LGBT no Brasil. Sociedade e Estado, 27(2), 289-312.

Ministério da Mulher, da Família e dos Direitos Humanos (2018). 4ạ Conferência Nacional LGBT será realizada em 2019 [Website]. Disponível em https://www.mdh.gov.br/ todas-as-noticias/2018/julho/4a-conferencia-nacional-Igbt-sera-realizada-em-2019

Ministério da Saúde (2009). Carta de Brasília. In Seminário Nacional Diversidade de Sujeitos e Igualdade de Direitos no SUS. Brasília.

Montenegro, L., Velasque, L., Legrand, S., Whetten, K., Mattos, R. De, \& Rafael, R. (2019). Public health, HIV care and prevention, human rights and democracy at a crossroad in Brazil. AIDS and Behavior, 1(4). doi:http://dx.doi.org/10.1007/s10461-019-02470-3

Moscheta, M., Fébole, D., \& Anzolin, B. (2016). Visibilidade seletiva: A influência da heterossexualidade compulsória nos cuidados em saúde de homens gays e mulheres lésbicas e bissexuais. Saúde \& Transformação Social, 7(3), 71-83.

Moura, R., \& Pupo, A. (2019). STF deve formar maioria para enquadrar homofobia como racismo. Estadão. [Website]. Disponível em https://politica.estadao.com.br/blogs/ fausto-macedo/stf-deveformar-maioria-para-enquadrar-homofobia-como-racismo/

Organização das Nações Unidas. (2018). Páginas Trans: Guia de acesso a direitos e serviços para pessoas trans. Brasília: Nações Unidas no Brasil.

Paranhos, F. R. L. (2017). Bioética principialista 1. Thaumazein, 10(19), 39-54.

Perucchi, J., Brandão, B. C., Magno, C., Berto, G., Rodrigues, F. D., \& Augusto, J. (2014). Brazil's Unified Health System (SUS) and its treatment for transgender people. Psychology, 5(9), 1090-1094. doi:http://dx.doi.org/10.4236/psych.2014.59121

Polejack, L., Totugui, M., Gomes, P., \& Conceição, M. (2015). Atuação do psicólogo nas políticas públicas de saúde: caminhos, desafios e possibilidades. In L. Polejack, A. Vaz, P. Gomes \& V. Wichrowski (Org.), Psicologia e políticas públicas na saúde: Experiências, reflexões, interfaces e desafios (1a ed., pp. 31-48). Porto Alegre: Rede Unida.

Popadiuk, G. S., Oliveira, D. C., \& Signorelli, M. C. (2017). A Política Nacional de Saúde Integral de Lésbicas, Gays, Bissexuais e Transgêneros (LGBT) e o acesso ao Processo Transexualizador no Sistema Único de Saúde (SUS): avanços e desafios. Ciência \& Saúde Coletiva, 22(5), 1509-1520. doi:http://dx.doi.org/10.1590/1413-81232017225.32782016 Ministério da Mulher, da Família e dos Direitos Humanos. Secretaria Especial dos Direitos Humanos. (2008). Anais da 1 a Conferência Nacional de Gays, Lésbicas, Bissexuais, Travestis e Transexuais. Brasília. Disponível em https://www.mdh.gov.br/informacao-ao-cidadao/ participacao-social/old/cncd-lgbt/conferencias/anais-1a-conferencia-nacional-lgbt-2/ view

Resolução n. 26, de 28 de setembro de 2017. (2017). Dispõe sobre o II Plano Operativo (2017- 2019) da Política Nacional de Saúde Integral de Lésbicas, Gays, Bissexuais, Travestis e Transexuais (Política Nacional de Saúde Integral LGBT) no âmbito do Sistema Único de Saúde. Diário Oficial da União. 
Santos, A. R. D., Santos, R. M. M., Souza, M. L. D., Boery, R. N. S. D. O., Sena, E. L. D. S., \& Yarid, S. D. (2015). Implicações bioéticas no atendimento de saúde ao público LGBTT. Revista Bioética (Impressa), 23(2), 400-408.

Secretaria Especial de Direitos Humanos. (2016). Relatório de violência homofóbica no Brasil: Ano 2013. Brasília. Disponível em http://www.direito.mppr.mp.br/arquivos/File/ RelatorioViolenciaHomofobicaBR2013.pdf

Silva, J. W. S. B., Nobre, C. N., de Carvalho Bezerra, H. M., Duarte, K. V. N., \& de Macedo Quinino, L. R. (2017). Políticas públicas de saúde voltadas à população LGBT e à atuação do controle social. Espaço para Saúde, 18(1), 140-149. https://doi. org/10.5433/15177130-2017v18n1p140

De Souza, M. T., Da Silva, M. D., \& De Carvalho, R. (2010). Revisão integrativa: O que é e como fazer. Einstein, 8(1 Pt 1), 102-6.

Yogyakarta Principles. (2006). The Yogyakarta Principles.

Recebido em: 12/07/2019 última revisão em: 05/11/2019

Aceite final: 21/01/2020

\section{Sobre as autoras:}

Izabella Rodrigues Melo: Mestranda do Programa de Pós-Graduação em Psicologia Clínica e Cultura da Universidade de Brasília (UnB). Psicóloga. E-mail: izabella.rmelo@gmail.com, Orcid: https://orcid.org/0000-0001-5172-1148

Thatiane Hellen de Amorim: Graduanda em Psicologia pela Universidade de Brasília (UnB). E-mail: thati.amorim1@gmail.com, Orcid: https://orcid.org/0000-0002-0367-7952

Raquel Braga Garcia: Graduanda em Psicologia pela Universidade de Brasília (UnB). E-mail: raquelrbg504@gmail.com, Orcid: https://orcid.org/0000-0001-6473-1943

Larissa Polejack: Doutora em Psicologia. Professora de Magistério Superior da Universidade de Brasília (UnB). E-mail: larissapolejack@hotmail.com, Orcid: https://orcid.org/0000-0002-0506-1721

Eliane Maria Fleury Seidl: Doutora em Psicologia, professora de magistério superior da Universidade de Brasília (UnB). E-mail: eliane.seidl@gmail.com, Orcid: https://orcid.org/0000-0002-1942-5100 